\title{
Mechanochemistry enables optical-electrical multifunctional response and tunability in two-dimensional hybrid perovskites
}

\author{
Zhi-Xu Zhang ${ }^{1}$, Chang-Yuan Su${ }^{1}$, Ji-Xing Gao ${ }^{2}$, Tie Zhang ${ }^{1}$ and Da-Wei Fu ${ }^{1,2^{*}}$
}

\begin{abstract}
Two-dimensional (2D) organic-inorganic hybrid perovskites (OIHPs) have attracted phenomenal attention because of their superior optoelectronic performances. The combination of their structural tunability and material stability offers an unprecedented opportunity to engineer materials with unique functionalities. However, developing a rapid and effective design method for introducing luminescence into dielectric switch and realizing controllable regulation has been an enormous challenge. Thus far, materials with tunable optoelectronic multichannel response have not been successfully implemented. In this study, we successfully developed a facile and effective mechanochemical method for realizing the integration and regulation of luminescence and dielectric switch in $2 \mathrm{D}$ perovskites, which is unprecedented for the design of dielectric switching materials. The mild external mechanical stimuli enabled the formation of $\mathrm{Mn}^{2+}$ ion-doped $2 \mathrm{D}$ hybrid perovskites (Cyclopropylammonium) ${ }_{2} \mathrm{~Pb}_{1-x} \mathrm{Mn}_{x} \mathrm{Br}_{4}$ with excellent dielectric switch and rapidly controllable luminescence of highly efficient blue light, white light, pink light, and orange light. This work will provide a new perspective on the rapid and effective design of multifunctional materials and can inspire the future development of low-cost and high-efficiency electronics.
\end{abstract}

Keywords: 2D hybrid perovskite, tunable optoelectronic response, mechanochemistry, multifunctional material

\section{INTRODUCTION}

As a new area of current research, two-dimensional (2D) organic-inorganic hybrid perovskites (OIHPs) have attracted phenomenal research interest because of their intriguing applications in high-efficiency solar cells, light- emitting diodes, lasers, and photodetectors [1-6]. The structurally $2 \mathrm{D}$ perovskites are more stable in air and light than the 3D analogues, which endows the former with a greater application potential in optoelectronic devices [79]. In particular, the perovskite-based solid-state lighting materials are highly desired as attractive solutions to the disadvantages of traditional fluorescent lighting sources $[10,11]$. Compared with the $3 \mathrm{D}$ analogues, the 2D OIHPs with relaxed structural constraints open a richer platform for material design and property tuning, providing more possibilities for their functional diversity [12-15]. Nevertheless, the effective design and regulation of $2 \mathrm{D}$ OIHPs have been a huge challenge, owing to the complexity of multifunctional integration and accidental prediction of the properties for functional materials.

Responsive switching materials, designated as switchable dielectrics, whose physical properties can be reversibly switched between different relatively stable states under external stimuli, have been extensively investigated because of their widespread applications, such as in thermoelectric switch, data communication, thermal energy storage, and signal processing [16-22]. However, most reported switchable dielectrics still suffer from single functional response performance, cumbersome preparation processes, low operating temperature, and safety risks [23-28]. To solve these issues and break the boundaries in generating various desired multifunctionalities, exploring a facile effective preparation method to integrate and regulate luminescence and switching characteristics is undoubtedly a highly attractive scientific undertaking. Doping transition metals, especially divalent manganese, into halide perovskites has

\footnotetext{
${ }^{1}$ Ordered Matter Science Research Center, Jiangsu Key Laboratory for Science and Applications of Molecular Ferroelectrics, Southeast University, Nanjing 211189, China

${ }^{2}$ Institute for Science and Applications of Molecular Ferroelectrics, Key Laboratory of the Ministry of Education for Advanced Catalysis Materials, Zhejiang Normal University, Jinhua 321004, China

* Corresponding author (email: dawei@seu.edu.cn)
} 
drawn significant research interest; it is thought to be an effective strategy to reduce toxicity and obtain new fascinating properties [29-32]. Up to now, the ${ }^{4} \mathrm{~T}_{1}{ }^{6} \mathrm{~A}_{1}$ transitions of $\mathrm{Mn}^{2+}$ with strong sensitized luminescence in 3D halide perovskites and nanocrystals, considering the energy transfer between the host and the dopant ions, have been extensively reported [33-35]. The combined strategy of doping with $\mathrm{Mn}^{2+}$ ions has been proposed as a useful means to improve the optical performance, whereas its valuable role in developing responsive switch has yet to be further explored [36-38]. In addition, the structural phase transition mechanisms of switchable dielectrics are mainly associated with the dynamic motion of organic cations in hybrid materials [39-42]. Given this, doping $\mathrm{Mn}^{2+}$ ions in low-dimensional semiconductor materials that contain suitable cations has the potential to enable multifunctionality in electric and optical channels.

Herein, we adopted a facile and effective mechanochemical method whereby $\mathrm{Mn}^{2+}$ ions are incorporated into 2D OIHPs to realize multifunctional response and the rapid regulation of responsive switching and luminescence. Considering the 2D purplish-blue-lighting perovskite $(\mathrm{CPA})_{2} \mathrm{PbBr}_{4}(\mathrm{CPA}=$ cyclopropylammonium $)$ and the dielectric switching behavior triggered by the unique cationic motion in orange-lighting perovskite $(\mathrm{CPA})_{2} \mathrm{MnBr}_{4}$, we used $(\mathrm{CPA})_{2} \mathrm{PbBr}_{4}$ as the active semiconductor host of the $\mathrm{Mn}^{2+}$ dopant ions (Fig. 1). As expected, the Mn-doped perovskite series were rapidly synthesized only by mild mechanical stimulus and showed fascinating luminescence of blue light, white light, pink light, and orange light. More strikingly, the $(\mathrm{CPA})_{2} \mathrm{~Pb}_{1-x} \mathrm{Mn}_{x} \mathrm{Br}_{4}(x=0.3,0.4,0.5)$ all exhibited excellent dielectric switch characteristics, achieving a dramatic enhancement of $99 \mathrm{~K}$ for the phase transition temperature $\left(T_{\mathrm{p}}\right)$, compared with $(\mathrm{CPA})_{2} \mathrm{MnBr}_{4}$. To the best of our knowledge, such a facile mechanochemical approach for obtaining and designing multifunctional responsive switching materials is unprecedented. This pioneering work, which integrates the merits of dielectric switching, symmetry breaking, doping, and luminescence into one molecular device unit by a simple mechanochemical method, will reveal new insights into smart optical/electrical-responsive multifunctional materials.

\section{EXPERIMENTAL SECTION}

\section{Sample preparation}

Single crystals of $(\mathrm{CPA})_{2} \mathrm{MnBr}_{4}$ and $(\mathrm{CPA})_{2} \mathrm{PbBr}_{4}$ were easily obtained by the slow evaporation of an $\mathrm{HBr}$ aqueous solution containing cyclopropylamine and the corresponding metal bromide at a 2:1 molar ratio. Furthermore, $(\mathrm{CPA})_{2} \mathrm{~Pb}_{1-x} \mathrm{Mn}_{x} \mathrm{Br}_{4} \quad(x=0,0.01,0.015$, $0.02,0.05,0.1,0.15,0.2,0.3,0.4,0.5)$ perovskite series were rapidly synthesized by mechanical grinding at room temperature (Fig. 1). The synthesis procedures of these materials are detailed in Supplementary information.

\section{Material characterizations and theoretical calculations}

The single-crystal X-ray diffraction (XRD), powder XRD (PXRD), differential scanning calorimetry (DSC) measurements, dielectric measurements, Hirshfeld surface calculations, photoluminescence measurements, and computational methods are comprehensively described in Supplementary information. CCDC 1991294-1991296 contains the supplementary crystallographic data for this paper. These data are freely accessible from The Cambridge Crystallographic Data Centre through www.ccdc. cam.ac.uk/data_request/cif.

\section{RESULTS AND DISCUSSION}

Single-crystal X-ray structure determinations were performed to study the structural details. The perovskites $(\mathrm{CPA})_{2} \mathrm{PbBr}_{4}$ and $(\mathrm{CPA})_{2} \mathrm{MnBr}_{4}$ were isostructural, adopting a layered $2 \mathrm{D}$ perovskite structure, in which the infinite and staggered layers of corner-sharing $\mathrm{XBr}_{6}(\mathrm{X}=$ $\mathrm{Pb}, \mathrm{Mn}$ ) octahedron were separated by $\mathrm{CPA}$ cation bi-

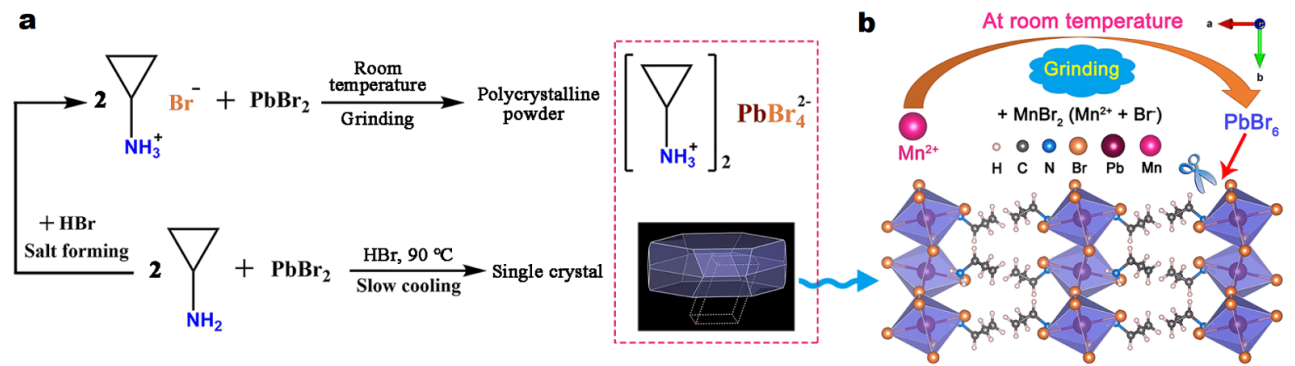

Figure 1 (a) Experimental illustration diagram for the synthesis of $(\mathrm{CPA})_{2} \mathrm{PbBr}_{4}$ via mechanical grinding and solution processing method. (b) Experimental illustration of $\mathrm{Mn}^{2+}$ ions entering 2D layered perovskite (CPA) ${ }_{2} \mathrm{PbBr}_{4}$. 
layers (Fig. S1). Each central metal atom is linked with six $\mathrm{Br}$ atoms to form a slightly twisted octahedron, and the protonated CPA cations are anchored to the halide ions of the octahedral structure through $\mathrm{N}-\mathrm{H}$...Br hydrogen bonds (Fig. 2). Differentially, at $293 \mathrm{~K}$, the (CPA) ${ }_{2} \mathrm{PbBr}_{4}$ crystallized in the monoclinic space group $P 2_{1} / c$, while $(\mathrm{CPA})_{2} \mathrm{MnBr}_{4}$ located in the tetragonal space group $\mathrm{P}_{2} / \mathrm{ncm}$ (Table S1). Moreover, the CPA cations in $(\mathrm{CPA})_{2} \mathrm{PbBr}_{4}$ are ordered in a static state, while those in $(\mathrm{CPA})_{2} \mathrm{MnBr}_{4}$ show a dynamically disordered state. Interestingly, $(\mathrm{CPA})_{2} \mathrm{MnBr}_{4}$ exhibits reversible structural phase transitions at 208.8 and $232.4 \mathrm{~K}$. Moreover, $(\mathrm{CPA})_{2} \mathrm{MnBr}_{4}$ transforms into the orthorhombic space group $P c a 2_{1}$ at $143 \mathrm{~K}$ and its structure is totally ordered.

The hydrogen bonds $(\mathrm{N}-\mathrm{H} \cdots \mathrm{Br})$ between the terminus of organic cations and the end of inorganic layers can affect the structural arrangement, which is the cause of the staggered conformation of the inorganic lattice in (CPA $)_{2} \mathrm{PbBr}_{4}$ and (CPA) ${ }_{2} \mathrm{MnBr}_{4}$. As shown in Fig. 2a, b, the CPA cations of (CPA) ${ }_{2} \mathrm{MnBr}_{4}$ are positioned in the center of the diagonal of the square, while those of $(\mathrm{CPA})_{2} \mathrm{PbBr}_{4}$ are very close to an obtuse angle position of the parallelogram. With the temperature decreased to $143 \mathrm{~K}$, the hydrogen bonds in the ordered low-symmetrical (CPA) ${ }_{2} \mathrm{MnBr}_{4}$ become stronger, causing a slight distortion of $\left[\mathrm{MnBr}_{6}\right]$ octahedron layers, and the CPA cations slightly deviate from the center of the parallelo- gram (Fig. 2c). The hydrogen bonds in (CPA) ${ }_{2} \mathrm{PbBr}_{4}$ are stronger than those in (CPA) ${ }_{2} \mathrm{MnBr}_{4}$ (Table S2), resulting in a more distorted lattice structure of the $\left[\mathrm{PbBr}_{6}\right]$ octahedron layers (Fig. 2e, f). The bilayers of CPA cations are anchored to the space between the inorganic layers by some hydrogen bonds, which also results in long interlayer halide-halide distances of $6.269 \AA$ for $(\mathrm{CPA})_{2} \mathrm{PbBr}_{4}$, $6.261 \AA$ for $(\mathrm{CPA})_{2} \mathrm{MnBr}_{4}$ at $293 \mathrm{~K}$ and $6.236 \AA$ for $(\mathrm{CPA})_{2} \mathrm{MnBr}_{4}$ at $143 \mathrm{~K}$, respectively. The distance between inorganic layers of $(\mathrm{CPA})_{2} \mathrm{PbBr}_{4}$ is so close to that of $(\mathrm{CPA})_{2} \mathrm{MnBr}_{4}$, making the mechanical grinding strategy to dope Mn feasible and easy to implement.

To further clarify the hydrogen bonding effect between cations and metal skeletons on structural characteristics and properties, both Hirshfeld surfaces and 2D-fingerprint plots of CPA cations in $(\mathrm{CPA})_{2} \mathrm{PbBr}_{4}$ at $293 \mathrm{~K}$, (CPA) ${ }_{2} \mathrm{MnBr}_{4}$ at 143 and $293 \mathrm{~K}$ are discussed (Fig. 3 and Fig. S2) $[43,44]$. The interactions between the CPA cation and surrounding molecules in $(\mathrm{CPA})_{2} \mathrm{PbBr}_{4}$ are stronger than those in $(\mathrm{CPA})_{2} \mathrm{MnBr}_{4}$, based on the Hirshfeld surfaces, in which red, white, and blue are used to distinguish the contacts shorter than, equal to, and longer than the van der Waals distances, respectively (Fig. 3). The close contacts from elements of $\mathrm{H}_{\text {inside }}-\mathrm{Br}_{\text {outside }}$ (the hydrogen bonding contacts between the $\mathrm{N}$ atoms of CPA cations and the end of inorganic layers) are highlighted in the $2 \mathrm{D}$ fingerprint plots. In $2 \mathrm{D}$ fingerprint plots, each
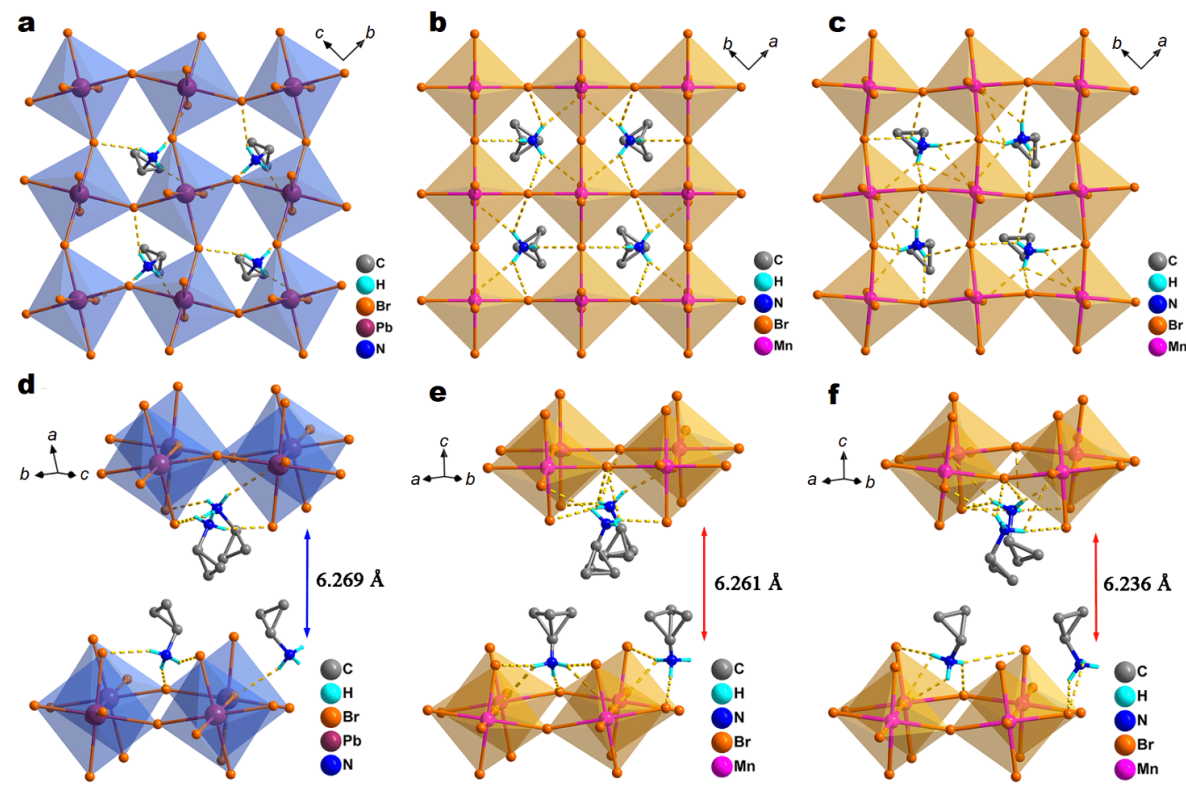

Figure 2 (a) Magnified views of the hydrogen bridging geometries of (a) $(\mathrm{CPA})_{2} \mathrm{PbBr}_{4}$ at $293 \mathrm{~K}$, (b) $(\mathrm{CPA})_{2} \mathrm{MnBr}_{4}$ at $293 \mathrm{~K}$ and (c) $(\mathrm{CPA})_{2} \mathrm{MnBr}_{4}$ at $143 \mathrm{~K}$, showing the octahedron of $\left[\mathrm{PbBr}_{6}\right]$ in comparison with $\left[\mathrm{MnBr}_{6}\right]$ and the position of $\mathrm{CPA}$ cations relative to the corner-sharing octahedrons. Structure fragments of (d) $(\mathrm{CPA})_{2} \mathrm{PbBr}_{4}$ at $293 \mathrm{~K}$, (e) $(\mathrm{CPA})_{2} \mathrm{MnBr}_{4}$ at $293 \mathrm{~K}$, and (f) $(\mathrm{CPA})_{2} \mathrm{MnBr}_{4}$ at $143 \mathrm{~K}$, showing the hydrogen bonding network between the $\mathrm{CPA}$ cations and the corresponding inorganic skeleton in perovskites. 

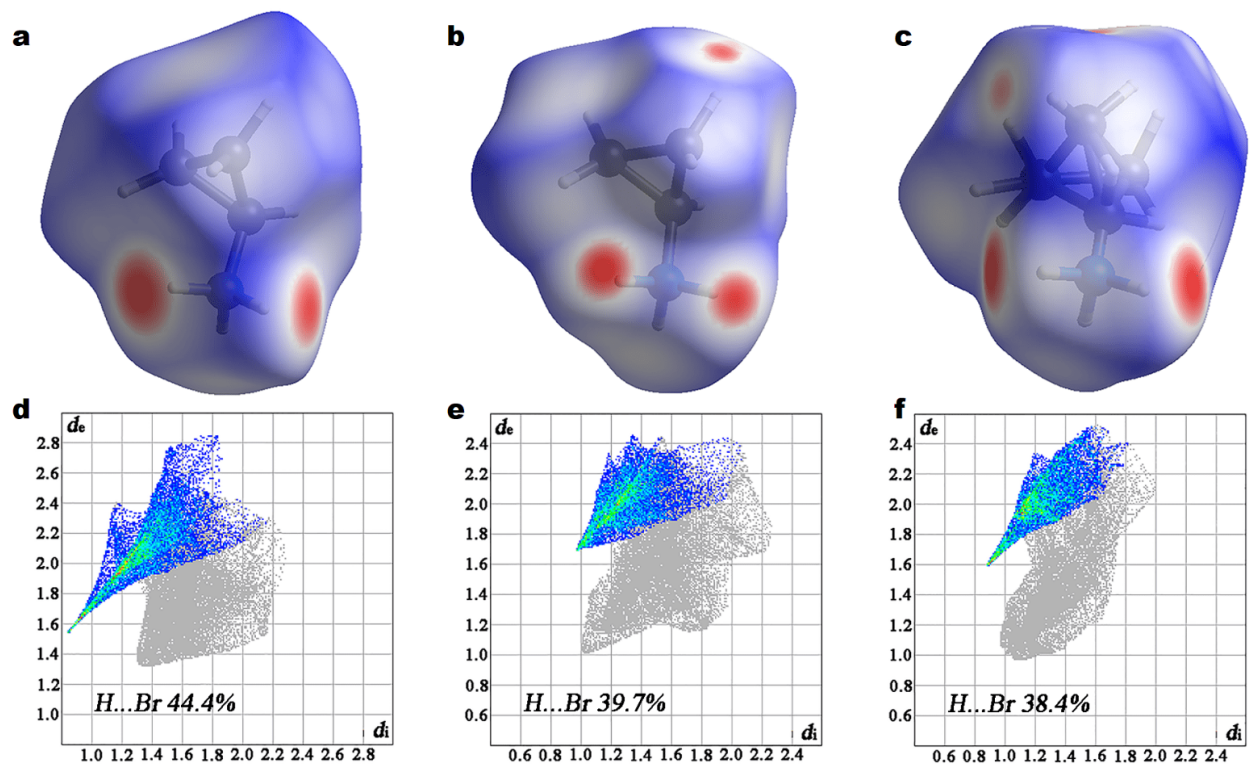

Figure 3 (a) Comparison for Hirshfeld surfaces of CPA cation in (a) $(\mathrm{CPA})_{2} \mathrm{PbBr}_{4}$ at $293 \mathrm{~K}$, (b) $(\mathrm{CPA})_{2} \mathrm{MnBr}_{4}$ at $143 \mathrm{~K}$ and $(\mathrm{c})(\mathrm{CPA})_{2} \mathrm{MnBr}_{4}$ at $293 \mathrm{~K}$. Close contacts are highlighted from elements of Hinside-Broutside in (d) $(\mathrm{CPA})_{2} \mathrm{PbBr}_{4}$ at $293 \mathrm{~K}$, (e) $(\mathrm{CPA})_{2} \mathrm{MnBr}_{4}$ at $143 \mathrm{~K}$ and (f) $(\mathrm{CPA})_{2} \mathrm{MnBr}_{4}$ at $293 \mathrm{~K}$.

point represents an individual pair $\left(d_{\mathrm{i}}, d_{\mathrm{e}}\right)$, reflecting the distances to the nearest atom inside $\left(d_{\mathrm{i}}\right)$ and outside $\left(d_{\mathrm{e}}\right)$ of the Hirshfeld surface, and the frequency of occurrence for these points correspond to the color from blue (low), through green, to red (highest). Notably, not only is the minimum $\left(d_{\mathrm{i}}, d_{\mathrm{e}}\right)$ of the $\mathrm{N}-\mathrm{Br}$ contacts in $(\mathrm{CPA})_{2} \mathrm{PbBr}_{4}$ $(0.84,1.55)$ shorter than those in $(\mathrm{CPA})_{2} \mathrm{MnBr}_{4}(0.96$, 1.70), but the surface area of the contacts in (CPA $)_{2} \mathrm{PbBr}_{4}$ $(44.4 \%)$ is also larger than those in (CPA) ${ }_{2} \mathrm{MnBr}_{4}(39.7 \%)$, confirming that the stronger hydrogen bonding is associated with the more distorted lattice structure of the $\left[\mathrm{PbBr}_{6}\right]$ octahedron layers. Considering that the orderdisorder transition of CPA cations plays a significant role in phase transition, this stronger hydrogen bonding contacts also limit the dynamic motion of CPA cations, which makes it difficult for $(\mathrm{CPA})_{2} \mathrm{PbBr}_{4}$ to undergo a phase transition under thermal stimulation.

The luminescence property of OIHPs is generally associated with the structure of the inorganic layers. For $(\mathrm{CPA})_{2} \mathrm{PbBr}_{4}$, the $\mathrm{Pb}-\mathrm{Br}-\mathrm{Pb}$ bond angle is $148.25^{\circ}$, much deviated from $180^{\circ}$ (Table S3), indicating a serious structural distortion inside the inorganic skeleton. In contrast, the $\mathrm{Mn}-\mathrm{Br}-\mathrm{Mn}$ bond angles of $(\mathrm{CPA})_{2} \mathrm{MnBr}_{4}$ at $293 \mathrm{~K}$ are $161.08^{\circ}$ and $180^{\circ}$, which are closer to the ideal octahedron, consistent with its high symmetry. Moreover, the dynamic changes in cations can also affect the inorganic skeleton. At $143 \mathrm{~K}$, the $\mathrm{Mn}-\mathrm{Br}-\mathrm{Mn}$ bond angles are changed to $161.33^{\circ}$ and $163.54^{\circ}$, indicating a very slight distortion. From these structural results, the phase transition mechanism of $(\mathrm{CPA})_{2} \mathrm{MnBr}_{4}$ can be mainly attributed to the order-disorder transition of CPA cations.

Based on the information of crystal structures, the high distortion of the inorganic layer in $(\mathrm{CPA})_{2} \mathrm{PbBr}_{4}$ perovskite results in a band-edge purplish-blue-light emission, whereas the orange emission of $(\mathrm{CPA})_{2} \mathrm{MnBr}_{4}$ is attributed to the ${ }^{4} \mathrm{~T}_{1} \rightarrow{ }^{6} \mathrm{~A}_{1}$ transition of $\mathrm{Mn}^{2+}$ [35,45]. To control luminescence characteristics, we prepared a series of perovskites by mixing the $(\mathrm{CPA})_{2} \mathrm{PbBr}_{4}$ and $(\mathrm{CPA})_{2^{-}}$ $\mathrm{MnBr}_{4}$ through a simple mechanochemical route. PXRD measurements were performed to confirm and study the (CPA $)_{2} \mathrm{~Pb}_{1-x} \mathrm{Mn}_{x} \mathrm{Br}_{4}$ perovskite series. Fig. $4 \mathrm{a}$ and Fig. S3 show the PXRD patterns of $(\mathrm{CPA})_{2} \mathrm{~Pb}_{1-x} \mathrm{Mn}_{x} \mathrm{Br}_{4}$ with various $\mathrm{Mn}^{2+}$ concentrations. The Pawley refinements for all these PXRD patterns reveal a monoclinic unit cell with a point group 2/m (Figs S4 and S5) [46,47]. The structural refinement results show that the unit cell volumes tended to decrease with the increase in $\mathrm{Mn}^{2+}$ concentrations (Fig. 4b), indicating that the lattice positions of $\mathrm{Pb}^{2+}$ are gradually substituted by $\mathrm{Mn}^{2+}$ ions, because the ionic radius of $\mathrm{Mn}^{2+}$ is smaller than that $\mathrm{Pb}^{2+}$. There is no significant difference between the PXRD patterns of (CPA) $)_{2} \mathrm{PbBr}_{4}$ to (CPA) ${ }_{2} \mathrm{~Pb}_{0.8} \mathrm{Mn}_{0.2} \mathrm{Br}_{4}$. Notably, as the $\mathrm{Mn}^{2+}$ concentration continues to increase, the PXRD pattern of $(\mathrm{CPA})_{2} \mathrm{~Pb}_{0.7} \mathrm{Mn}_{0.3} \mathrm{Br}_{4}$ begins to show noticeable differences. The phenomenon of $(\mathrm{CPA})_{2} \mathrm{~Pb}_{0.6} \mathrm{Mn}_{0.4} \mathrm{Br}_{4}$ and 

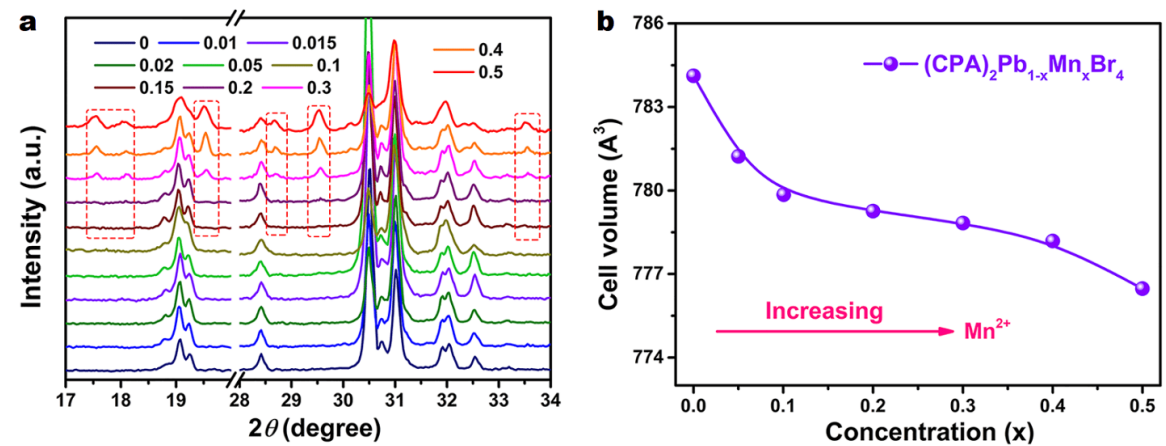

Figure 4 (a) High-resolution PXRD patterns for the (CPA) $\mathrm{Pb}_{1-x} \mathrm{Mn}_{x} \mathrm{Br}_{4}(x=0,0.01,0.015,0.02,0.05,0.1,0.15,0.2,0.3,0.4,0.5)$ perovskite series. (b) Unit cell volumes with different $\mathrm{Mn}^{2+}$ doping concentrations.

$(\mathrm{CPA})_{2} \mathrm{~Pb}_{0.5} \mathrm{Mn}_{0.5} \mathrm{Br}_{4}$ are the same as that of $(\mathrm{CPA})_{2} \mathrm{~Pb}_{0.7^{-}}$ $\mathrm{Mn}_{0.3} \mathrm{Br}_{4}$, except for a slight shift of diffraction peaks (Fig. 4a). From the comparison for the PXRD patterns of $(\mathrm{CPA})_{2} \mathrm{~Pb}_{0.5} \mathrm{Mn}_{0.5} \mathrm{Br}_{4}, \quad(\mathrm{CPA})_{2} \mathrm{MnBr}_{4}$, and $(\mathrm{CPA})_{2} \mathrm{PbBr}_{4}$ (Fig. S6), after doping $\mathrm{Mn}^{2+}$ ions on (CPA) ${ }_{2} \mathrm{PbBr}_{4}$, the PXRD pattern shows some changes; for example, some diffraction peaks emerge at $17.56^{\circ}, 18.10^{\circ}, 19.56^{\circ}, 28.68^{\circ}$, $29.54^{\circ}, 33.56^{\circ}$, and $46.10^{\circ}$, and some diffraction peaks show shifts and splits. The newly emerged diffraction peaks show weak intensity, making the PXRD patterns feature a slight change, which should be attributed to the fact that the entry of Mn did not cause large damage to the lattice; the lattice still maintain the $2 \mathrm{D}$ structure. The PXRD patterns of (CPA) ${ }_{2} \mathrm{PbBr}_{4}$ and (CPA) ${ }_{2} \mathrm{~Pb}_{0.5} \mathrm{Mn}_{0.5} \mathrm{Br}_{4}$ (Fig. S7) exhibit a series of intense sharp $(a 00)(a=1-6)$ diffraction peaks, indicating the perfect periodicity of the stacking along the $\langle 100>$ direction as well as high crystallinity. In addition, the refinement results of the PXRD patterns can also prove the pure phase of the highly doped samples. The variation in the PXRD patterns reveals that the entry of $\mathrm{Mn}$ into the lattice caused the deformation of the inorganic skeleton, possibly affecting the state of the cation, which consequently results in the optical-electrical multifunctional response and tunability.

Considering the variation in PXRD patterns, we carried out DSC measurements to detect the phase transitions. As shown in Fig. 5a, two pairs of thermal anomaly peaks are observed for (CPA $)_{2} \mathrm{MnBr}_{4}$ upon heating/cooling runs, indicative of two reversible continuous structural phase transitions at $\sim 209$ and $\sim 232 \mathrm{~K}$. Remarkably, the $(\mathrm{CPA})_{2^{-}}$ $\mathrm{Pb}_{1-x} \mathrm{Mn}_{x} \mathrm{Br}_{4}(x=0.3,0.4,0.5)$ all exhibit an obvious phase transition at $\sim 331 \mathrm{~K}$ (Fig. $5 \mathrm{~b}$ and Fig. S8), suggesting that the mechanical grinding strategy is indeed effective; that is, the incorporation of $\mathrm{Mn}^{2+}$ into $(\mathrm{CPA})_{2}-$ $\mathrm{PbBr}_{4}$ can successfully induce the phase transition and improve the $T_{\mathrm{p}}$. These sharp exothermic/endothermic peaks and wide thermal hysteresis reveal first-order phase transition. For convenience, the phase below $T_{\mathrm{p}}$ is regarded as the "low-temperature phase" (LTP), and the phase above $T_{\mathrm{p}}$ as the "high-temperature phase" (HTP). In $2 \mathrm{D}$ hybrid perovskite structures, the organic cations and inorganic components are connected by some weak interactions (e.g., hydrogen bonding) and affect each other; these weak interactions and mutual effect are related and crucial to perovskite properties. With the increase in $\mathrm{Mn}^{2+}$ ions, the lattice positions of $\mathrm{Pb}^{2+}$ are gradually replaced by $\mathrm{Mn}^{2+}$ ions, which causes changes in the inorganic components, and thereby affect the states of CPA cations. As mentioned above, at room temperature, the CPA cations in $(\mathrm{CPA})_{2} \mathrm{PbBr}_{4}$ show statically ordered state, while those in (CPA) ${ }_{2} \mathrm{MnBr}_{4}$ are dynamically disordered. When the $\mathrm{Mn}^{2+}$ ion concentration reaches a certain value, the structural change of the perovskite is enough to cause a change in its properties, making the $T_{\mathrm{p}}$ sufficiently increase from $232 \mathrm{~K}$ in $(\mathrm{CPA})_{2} \mathrm{MnBr}_{4}$ to $331 \mathrm{~K}$ in $(\mathrm{CPA})_{2} \mathrm{~Pb}_{1-x} \mathrm{Mn}_{x} \mathrm{Br}_{4}(x=0.3,0.4,0.5)$. The structures and phase transition properties of $(\mathrm{CPA})_{2} \mathrm{~Pb}_{1-x} \mathrm{Mn}_{x} \mathrm{Br}_{4}(x$ $=0.3,0.4,0.5)$ are similar; therefore, we here take (CPA) $)_{2} \mathrm{~Pb}_{0.5} \mathrm{Mn}_{0.5} \mathrm{Br}_{4}$ as an example to further discuss the phase transition information and its device applications. As shown in Fig. 5c, the PXRD patterns show obvious changes from LTP to HTP, where the diffraction peaks at $17.5^{\circ}$ and $18.0^{\circ}$ disappear, a new diffraction peak was observed at $11.9^{\circ}$, and some diffraction peaks in highangle areas showed shifts and splits, meaning a structural phase transition occurred. In addition, the structure at $373 \mathrm{~K}$ is refined in a tetragonal unit cell with a point group $4 / \mathrm{mmm}$ (Fig. S9). The relationship of the cells at 273 and $373 \mathrm{~K}$ is $a_{\mathrm{LTP}} \approx b_{\mathrm{HTP}}-0.5 c_{\mathrm{HTP}}, b_{\mathrm{LTP}} \approx a_{\mathrm{HTP}}-c_{\mathrm{HTP}}$, $c_{\text {LTP }} \approx c_{\text {HTP }}(a, b$ and $c$ are cell parameters of crystal). The PXRD pattern obtained at $293 \mathrm{~K}$ is consistent with the 

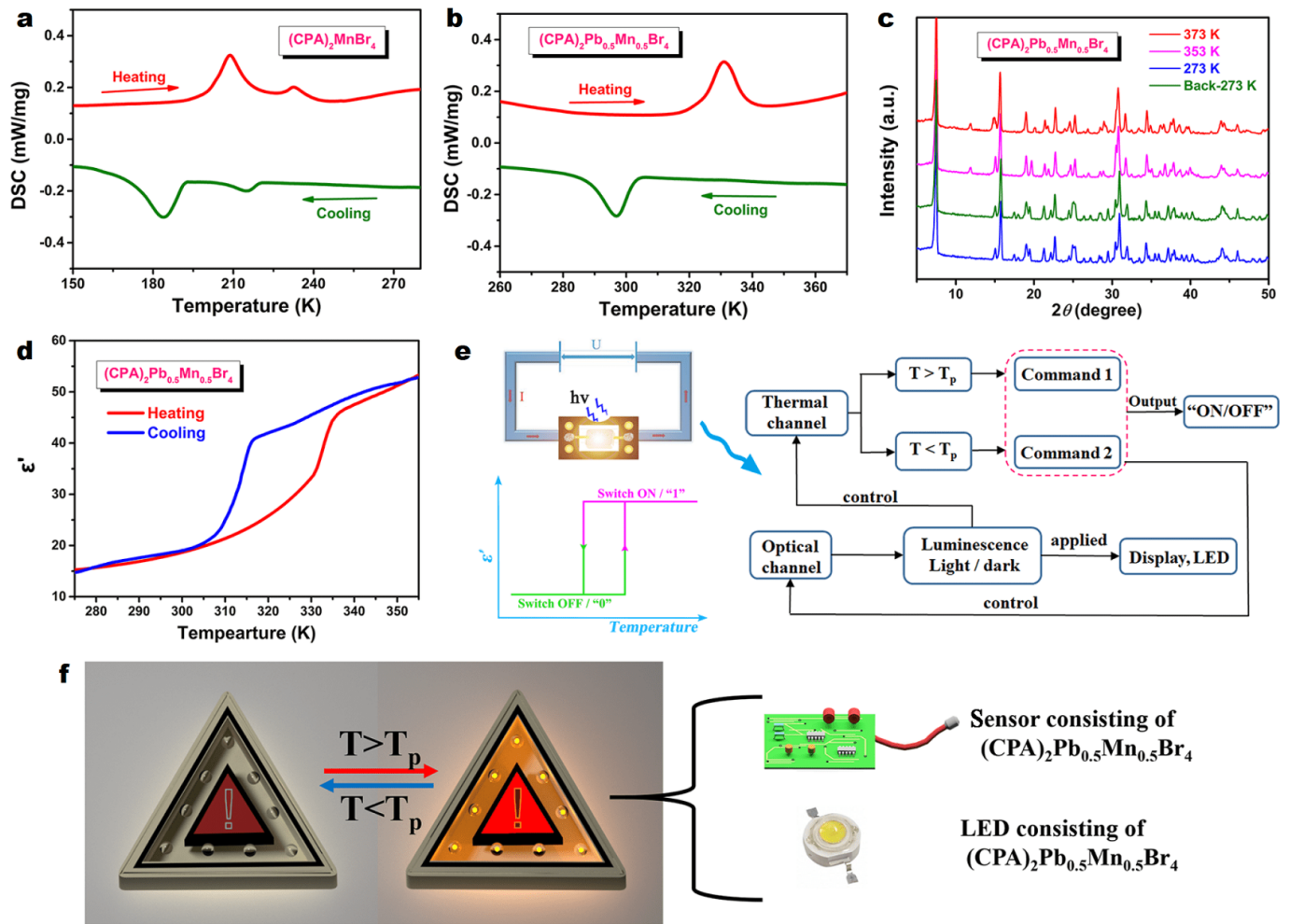

Sensor consisting of $(\mathrm{CPA})_{2} \mathrm{~Pb}_{0.5} \mathrm{Mn}_{0.5} \mathrm{Br}_{4}$

LED consisting of $(\mathrm{CPA})_{2} \mathrm{~Pb}_{0.5} \mathrm{Mn}_{0.5} \mathrm{Br}_{4}$

Figure 5 DSC curves of (a) (CPA) $)_{2} \mathrm{PbBr}_{4}$ and (b) $(\mathrm{CPA})_{2} \mathrm{~Pb}_{0.5} \mathrm{Mn}_{0.5} \mathrm{Br}_{4}$. (c) Variable-temperature PXRD patterns of $(\mathrm{CPA})_{2} \mathrm{~Pb}_{0.5} \mathrm{Mn}_{0.5} \mathrm{Br}_{4}$. (d) $\mathrm{The}^{\prime}$ of $(\mathrm{CPA})_{2} \mathrm{~Pb}_{0.5} \mathrm{Mn}_{0.5} \mathrm{Br}_{4}$ vs. temperature. (e) Schematic diagram of dielectric measurements on electrodes made of the sample, and logic diagram in optoelectronic smart-controlled device. (f) Simulated application of the studied optoelectronic dual response material as a smart sensor in a media alarm system.

one obtained upon cooling back to $293 \mathrm{~K}$, demonstrating the reversibility of the phase transition.

Dielectric permittivity as a function of temperature generally shows noticeable anomalies near $T_{\mathrm{p}}$. We performed temperature-dependent dielectric measurements on electrodes made of $(\mathrm{CPA})_{2} \mathrm{~Pb}_{0.5} \mathrm{Mn}_{0.5} \mathrm{Br}_{4}$ to study the application of the dielectric switching device. The real part of dielectric permittivity $\left(\varepsilon^{\prime}\right)$ for (CPA) ${ }_{2} \mathrm{~Pb}_{0.5} \mathrm{Mn}_{0.5} \mathrm{Br}_{4}$ undergoes a remarkable "step-like" anomaly at $\sim 330 \mathrm{~K}$ upon heating (Fig. 5d), consistent with the DSC results. The $\varepsilon^{\prime}$ exhibits a corresponding anomaly at $\sim 297 \mathrm{~K}$ in cooling mode, showing the excellent dielectric switching characteristics. The dielectric permittivity of $(\mathrm{CPA})_{2} \mathrm{~Pb}_{0.5^{-}}$ $\mathrm{Mn}_{0.5} \mathrm{Br}_{4}$ exhibits two distinct dielectric steady states and can undergo transition between high dielectric state (corresponding to HTP) and low dielectric state (corresponding to LTP), satisfying the operation of ON/OFF switching, which thus can be used as intelligent control devices driven by the thermal signal. As shown in Fig. 5e, the logic diagram displays the process of multichannel control in imaginary smart systems, combining photo- luminescence and switchable properties. In a single device unit, multiple commands can be simultaneously executed on multiple physical channels to meet multiple application requirements, and the channels can control one another to achieve automatic operation. Notably, realizing a high temperature dielectric switch and high stability has always been a great challenge, while the $(\mathrm{CPA})_{2} \mathrm{MnBr}_{4}$ is easy to deliquescent that maks it difficult to use in dielectric devices. The strategy of incorporating $\mathrm{Mn}^{2+}$ into (CPA $)_{2} \mathrm{PbBr}_{4}$ to construct (CPA) ${ }_{2} \mathrm{~Pb}_{0.5} \mathrm{Mn}_{0.5} \mathrm{Br}_{4}$ greatly improves the stability of dielectric devices and achieves a dramatic enhancement of $99 \mathrm{~K}$ for $T_{\mathrm{p}}$, which demonstrates the effectiveness of this strategy as a new way to design novel switchable materials, having great scientific significance for the further exploration of smart dielectric switches. For operational purposes of media alarm signals, under an external heat stimulus, the device would automatically identify or decode the optical/electrical signal and perform selective response from an "inactive" state to an "active" state at the critical point $\left(T_{\mathrm{p}}\right)$, and enable the full automation of the overall switching pro- 
cess based on different physical conditions (Fig. 5f).

To study the mechanism for Mn incorporation into the $\mathrm{Pb}$ site, we investigated the impurity formation energy of $\mathrm{Mn}^{2+}$ ions in the host $(\mathrm{CPA})_{2} \mathrm{PbBr}_{4}$ using density functional theory (DFT) calculations. The impurity formation energy $\left(E_{\mathrm{f}}\right)$ of a particular substitutional dopant is given by the equation of $E_{\mathrm{f}}=E($ doped $)-E($ pure $)+\mu_{\mathrm{Pb}}-\mu_{\mathrm{Mn}}$, where in this study $E$ (doped) and $E$ (pure) are the total energies of $(\mathrm{CPA})_{2} \mathrm{~Pb}_{0.7} \mathrm{Mn}_{0.3} \mathrm{Br}_{4}$ and $(\mathrm{CPA})_{2} \mathrm{PbBr}_{4}$, respectively, and $\mu_{\mathrm{Mn}}$ and $\mu_{\mathrm{Pb}}$ are the chemical potentials of substitutional $\mathrm{Mn}$ and $\mathrm{Pb}$ atoms, respectively. According to the calculation results (Table $\mathrm{S} 4$ ), the $E_{\mathrm{f}}$ of $(\mathrm{CPA})_{2}$ $\mathrm{Pb}_{0.7} \mathrm{Mn}_{0.3} \mathrm{Br}_{4}$ is $-3.52 \mathrm{eV}$, indicating that the doped compound could be easily formed, which further verifies the successful incorporation of $\mathrm{Mn}^{2+}$ into $(\mathrm{CPA})_{2} \mathrm{PbBr}_{4}$; that is, the phase transition and luminescent features can be rapidly changed by the simple grinding method at room temperature.

The luminescence properties of the $(\mathrm{CPA})_{2} \mathrm{~Pb}_{1-x} \mathrm{Mn}_{x} \mathrm{Br}_{4}$ perovskite series are readily tunable through the modulation of $\mathrm{Mn}^{2+}$ ion concentration by simple grinding. The pure $(\mathrm{CPA})_{2} \mathrm{PbBr}_{4}$ exhibits a narrow emission band peak at $\sim 414 \mathrm{~nm}$ (Fig. 6a), while the (CPA) ${ }_{2} \mathrm{MnBr}_{4}$ shows a broad emission band peak at $\sim 598 \mathrm{~nm}$ upon $365 \mathrm{~nm}$ excitation (Fig. S10). When the $\mathrm{Mn}^{2+}$ ions are incorporated into the host $(\mathrm{CPA})_{2} \mathrm{PbBr}_{4}$, $(\mathrm{CPA})_{2} \mathrm{~Pb}_{1-x} \mathrm{Mn}_{x} \mathrm{Br}_{4}(x>0)$ samples exhibit both a narrow emission and a broad emission band peak at $\sim 414$ and $\sim 598 \mathrm{~nm}$, respectively, as seen from the normalized emission spectra in Fig. 6a, b. Meanwhile, the ratio of narrow emission to broad emission decreases with increasing $\mathrm{Mn}^{2+}$ concentration because of the $\mathrm{Pb}^{2+}$ lattice
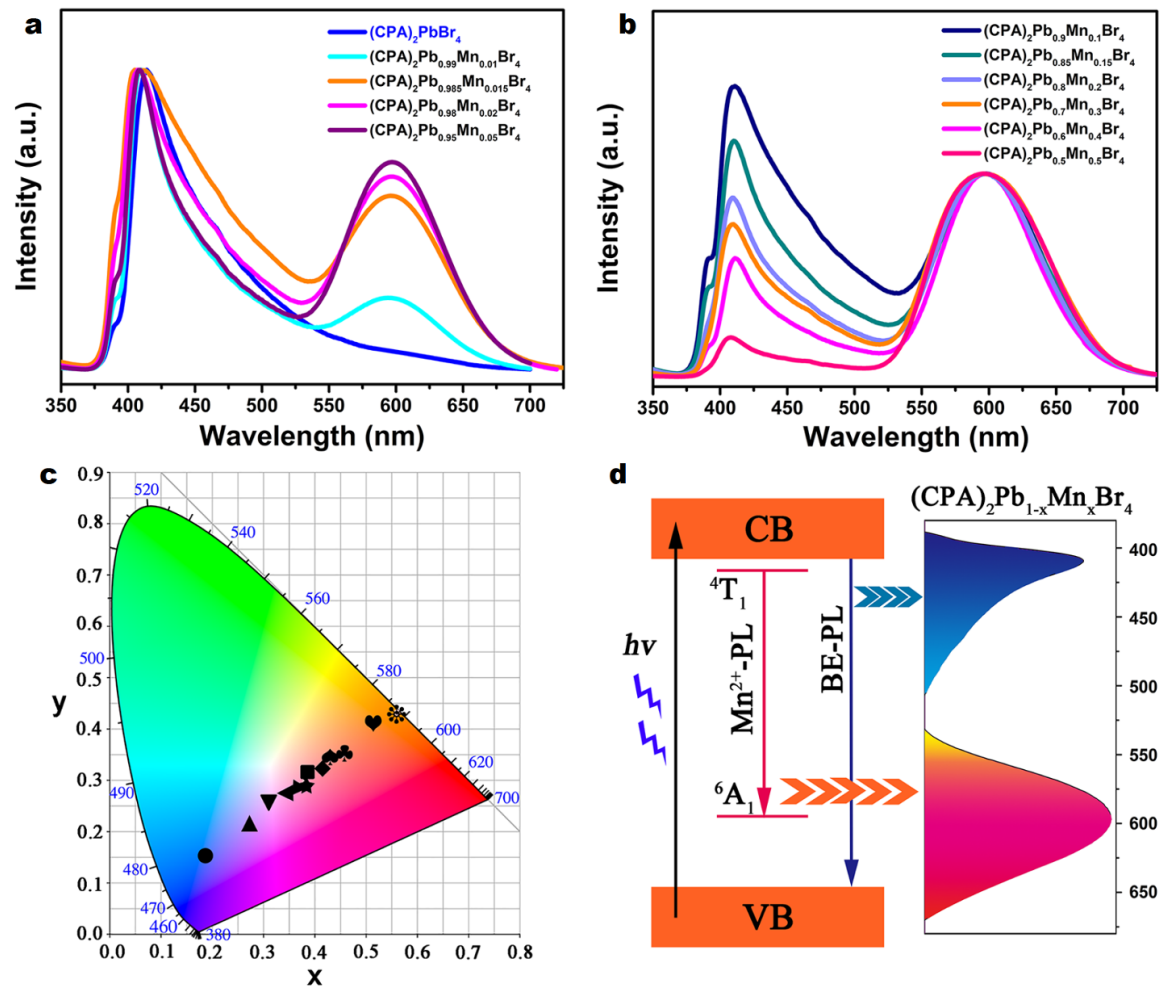

d
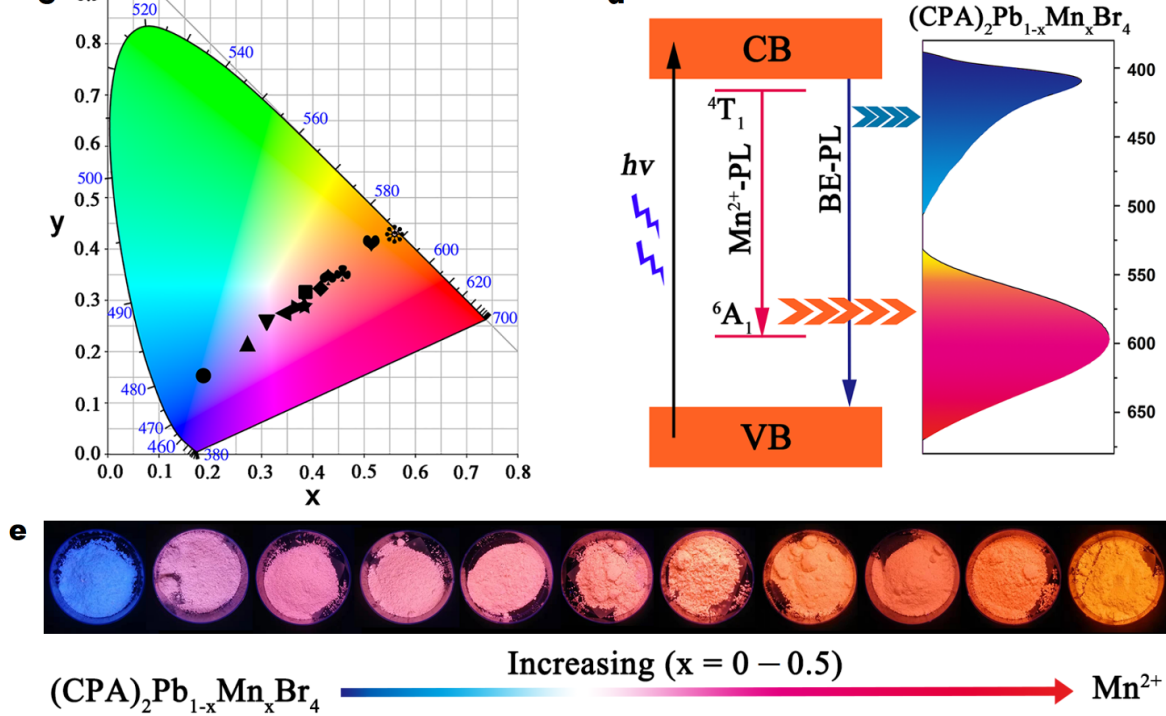

Figure $6(\mathrm{a}, \mathrm{b})$ The normalized emission spectra of $(\mathrm{CPA})_{2} \mathrm{~Pb}_{1-x} \mathrm{Mn}_{x} \mathrm{Br}_{4}$ perovskite series with different $\mathrm{Mn}^{2+}$ concentrations upon $365 \mathrm{~nm}$ excitation.

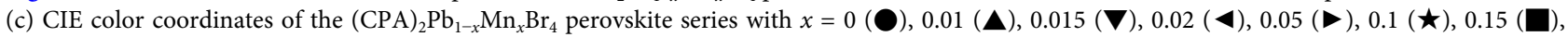
$0.2(\diamond), 0.3(\mathbf{\$}), 0.4(\mathbf{\bullet}), 0.5(\mathbf{\vee}), 1(*)$ in a 1931 color space chromaticity diagram. (d) Schematic energy diagram of different luminescence processes in $\mathrm{Mn}^{2+}$ ion-doped $(\mathrm{CPA})_{2} \mathrm{~Pb}_{1-x} \mathrm{Mn}_{x} \mathrm{Br}_{4}$. (e) Blue light, white light, pink light and orange light from the $(\mathrm{CPA})_{2} \mathrm{~Pb}_{1-x} \mathrm{Mn}_{x} \mathrm{Br}_{4}$ perovskite series under ultraviolet (UV) light with excitation wavelength $\lambda_{\mathrm{ex}}=365 \mathrm{~nm}$. 
positions being gradually replaced by $\mathrm{Mn}^{2+}$ ions, which also indicates that the effective fluorescence of $\mathrm{Mn}^{2+} \mathrm{can}$ be induced by energy transfers in this system. To confirm the existence of multiple luminescence centers and clarify the photophysical process, decay curves of $(\mathrm{CPA})_{2} \mathrm{PbBr}_{4}$ and $(\mathrm{CPA})_{2} \mathrm{~Pb}_{1-x} \mathrm{Mn}_{x} \mathrm{Br}_{4}(x=0.02,0.3,0.5)$ samples were measured at different monitoring wavelengths (Fig. S11). From the decay curve monitored at $414 \mathrm{~nm}$, the lifetime of band gap transition shows a continuous decrease from 7.93 to $3.43 \mathrm{~ns}$ with the increasing $\mathrm{Mn}^{2+}$ ion content, indicating energy transfer existed between the host and $\mathrm{Mn}^{2+}$. Especially, the lifetime at a monitored wavelength of $598 \mathrm{~nm}$ tends to decrease with the increase in $\mathrm{Mn}^{2+}$ concentration, suggesting the gradual enhancement of the energy transfer efficiency. The purplish-blue and orange emissions of $(\mathrm{CPA})_{2} \mathrm{~Pb}_{1-x} \mathrm{Mn}_{x} \mathrm{Br}_{4}$ series can be attributed to the coupling effects of band-edge emission and the ${ }^{4} \mathrm{~T}_{1} \rightarrow{ }^{6} \mathrm{~A}_{1}$ transition of $\mathrm{Mn}^{2+}$ due to an efficient energy transfer in this system (Fig. $6 \mathrm{~d}$ ).

The corresponding Commission Internationale de L'Eclairage (CIE) color coordinates calculated from the emission spectra of samples are shown in the 1931 color space chromaticity diagram (Fig. $6 \mathrm{c}$ and Fig. S12). The pure $(\mathrm{CPA})_{2} \mathrm{PbBr}_{4}$ has CIE coordinates of $(0.1877$,
0.1528), corresponding to purplish-blue emission. Moreover, the intermediate compounds $(\mathrm{CPA})_{2} \mathrm{~Pb}_{1-x} \mathrm{Mn}_{x} \mathrm{Br}_{4} \quad(x=0.015,0.02)$ exhibit white emissions with CIE color coordinates of $(0.3122,0.2623)$ and $(0.3447,0.2784)$ (Table S5). The correlated color temperatures of these materials indicate that the former emits a cold white light while the latter emits a warmer light. In addition, with the increase in $\mathrm{Mn}^{2+}$ ions, the (CPA) ${ }_{2} \mathrm{~Pb}_{0.7} \mathrm{Mn}_{0.3} \mathrm{Br}_{4}$ begins to enter into the pink light region until the $(\mathrm{CPA})_{2} \mathrm{~Pb}_{0.5} \mathrm{Mn}_{0.5} \mathrm{Br}_{4}$ emits an orange light. Moreover, the photoluminescence quantum yields (PLQYs) of (CPA) ${ }_{2} \mathrm{~Pb}_{1-x} \mathrm{Mn}_{x} \mathrm{Br}_{4}(x=0,0.02,0.3,0.5)$ are measured as $12.2 \%, 23.9 \%, 35.1 \%$ and $62.9 \%$, respectively (Fig. S13). It reaches a highly level in PLQY value, larger than that of most ever reported OIHPs as white-lightemitting materials $[10,11]$. As shown in Fig. 6e, by the regulation of the $\mathrm{Mn}^{2+}$ ion concentration at room temperature through the simple grinding method, luminescence of blue light, white light, pink light, and orange light from the $(\mathrm{CPA})_{2} \mathrm{~Pb}_{1-x} \mathrm{Mn}_{x} \mathrm{Br}_{4}$ perovskite series were easily realized.

To further investigate the optical properties and emission mechanisms, the electronic band structures and densities of states of $(\mathrm{CPA})_{2} \mathrm{PbBr}_{4}$ and $(\mathrm{CPA})_{2} \mathrm{~Pb}_{0.7} \mathrm{Mn}_{0.3^{-}}$
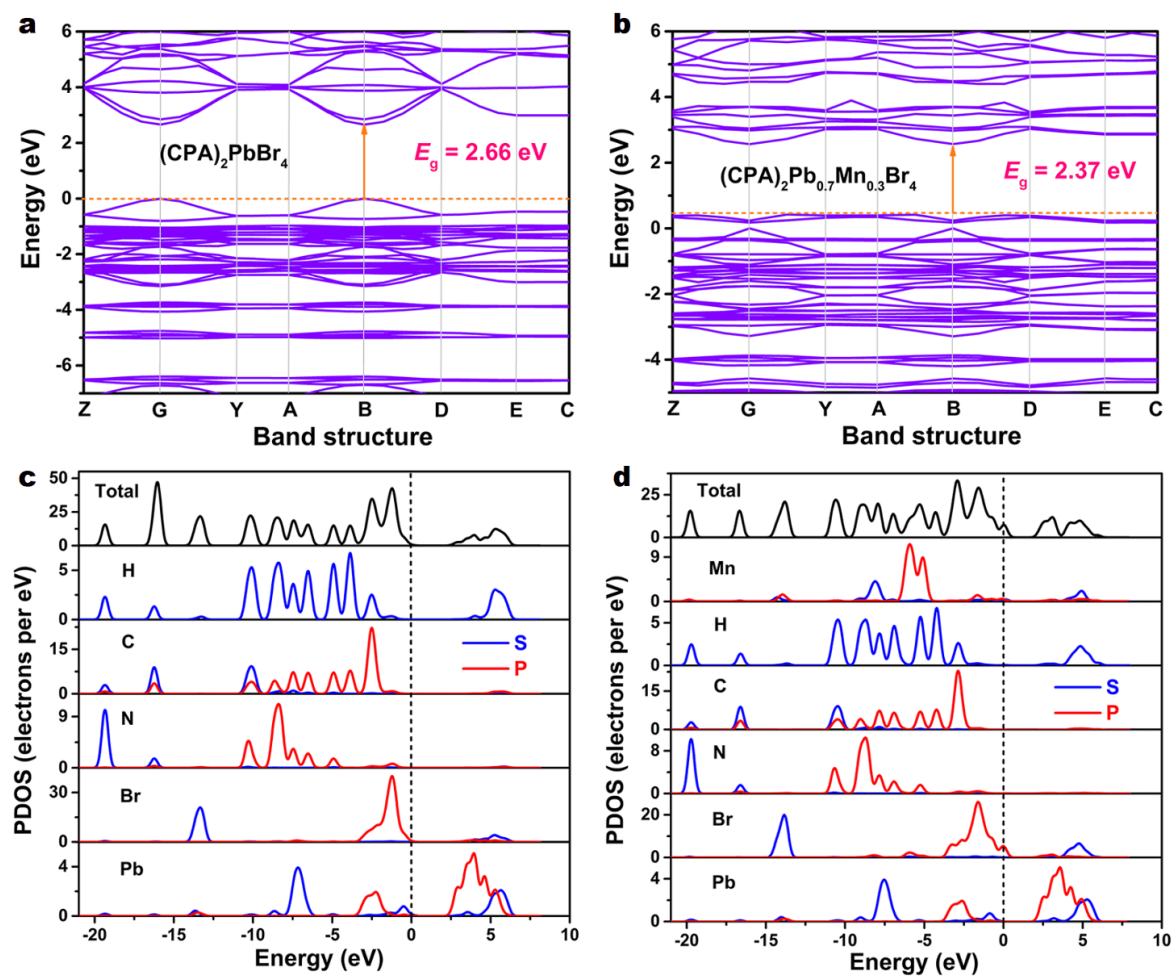

Figure 7 Electronic band structures of (a) the host $(\mathrm{CPA})_{2} \mathrm{PbBr}_{4}$ and (b) the doped sample $(\mathrm{CPA})_{2} \mathrm{~Pb}_{0.7} \mathrm{Mn}_{0.3} \mathrm{Br}_{4}$. The total and partial densities of states of (c) $(\mathrm{CPA})_{2} \mathrm{PbBr}_{4}$ and (d) $(\mathrm{CPA})_{2} \mathrm{~Pb}_{0.7} \mathrm{Mn}_{0.3} \mathrm{Br}_{4}$. 
$\mathrm{Br}_{4}$ were calculated by DFT [48-50]. As illustrated in Fig. 7, the calculated band gap of $(\mathrm{CPA})_{2} \mathrm{PbBr}_{4}$ is $2.66 \mathrm{eV}$, while the band gap value of $(\mathrm{CPA})_{2} \mathrm{~Pb}_{0.7} \mathrm{Mn}_{0.3} \mathrm{Br}_{4}$ is lower, $2.37 \mathrm{eV}$. This result agrees well with the measurements, although slightly different from the experimental values (3.04 and $2.82 \mathrm{eV}$ ), due to the limitation of DFT methods (Fig. S14). The optical parameters of lead hybrid perovskites are mainly determined by the overlapping of $\mathrm{s} / \mathrm{p}$ antibonding orbitals between the lead and halide ions, so this reduction in band gap implies that $\mathrm{Mn}^{2+}$ ions successfully entered the lattice to replace $\mathrm{Pb}^{2+}$ sites. The calculated partial densities of states (PDOS) projected onto the constituent elements in $(\mathrm{CPA})_{2} \mathrm{PbBr}_{4}$ and $(\mathrm{CPA})_{2} \mathrm{~Pb}_{0.7} \mathrm{Mn}_{0.3} \mathrm{Br}_{4}$ are displayed in Fig. $7 \mathrm{c}$, d. Both the top of valence bands and the bottom of conduction bands are only constituted by the orbitals of the inorganic part in $(\mathrm{CPA})_{2} \mathrm{PbBr}_{4}$, indicating that the fluorescence emission from self-trapping excitons mainly occurred within $\left[\mathrm{PbBr}_{6}\right]$ octahedra. After the $\mathrm{Mn}^{2+}$ incorporation, it can be observed in (CPA) $)_{2} \mathrm{~Pb}_{0.7} \mathrm{Mn}_{0.3} \mathrm{Br}_{4}$ that the $\mathrm{Mn}$ orbitals emerged at both the top of valence bands and the bottom of conduction bands, which demonstrates that photogenerated electrons could easily jump from the conduction band minimum to $\mathrm{Mn}$ together with energy transfer, and thereby causes the efficient luminescence of $\mathrm{Mn}^{2+}$ ions (Fig. 7d). In addition, the positions of the $\mathrm{Pb}$ and $\mathrm{Br}$ orbitals in the electronic structure are almost unchanged. This indicates that the $\mathrm{Mn}^{2+}$ ions introduced a new fluorescence emission wavelength without affecting the position of the intrinsic emission peak, resulting in the fascinating multiple light emissions.

\section{CONCLUSIONS}

In summary, to realize multifunctional integration and regulation of luminescence and responsive switching, we successfully adopted a facile and effective mechanochemical synthesis method whereby $\mathrm{Mn}^{2+}$ ions are incorporated into $(\mathrm{CPA})_{2} \mathrm{PbBr}_{4}$. The unique crystal structure of the $2 \mathrm{D}$ hybrid perovskite allowed the $\mathrm{Mn}^{2+}$ ions to rapidly enter the crystal lattice only by roomtemperature grinding to form $\mathrm{Mn}^{2+}$ ion-doped $2 \mathrm{D}$ hybrid perovskites $(\mathrm{CPA})_{2} \mathrm{~Pb}_{1-x} \mathrm{Mn}_{x} \mathrm{Br}_{4}$, showing the fascinating luminescence variations of blue-light, white-light, pinklight, and orange-light. The (CPA) ${ }_{2} \mathrm{~Pb}_{1-x} \mathrm{Mn}_{x} \mathrm{Br}_{4}(x=0.3$, $0.4,0.5)$ exhibit responsive dielectric switching characteristics at $331 \mathrm{~K}$, achieving a dramatic enhancement of $99 \mathrm{~K}$ for $T_{\mathrm{p}}$, compared with $(\mathrm{CPA})_{2} \mathrm{MnBr}_{4}$. Systematic characterizations and analyses indicate that the structural phase transition mechanisms are mainly ascribe to the order-disorder transition of CPA cations, and the pho- toluminescences corresponding to emissions at 414 and $598 \mathrm{~nm}$ are attributed to $(\mathrm{CPA})_{2} \mathrm{~Pb}_{1-x} \mathrm{Mn}_{x} \mathrm{Br}_{4}$ band-edge emission and the ${ }^{4} \mathrm{~T}_{1}{ }^{6} \mathrm{~A}_{1}$ transition of $\mathrm{Mn}^{2+}$ owing to an efficient energy transfer in the system. This work opens up new possibilities for the design and rapid preparation of multifunctional optoelectronic response materials via mechanochemical synthesis and would further benefit the development toward practical applications compatible with miniaturized multifunctional devices.

\section{Received 4 May 2020; accepted 10 July 2020;}

published online 22 October 2020

1 Chen P, Bai Y, Lyu M, et al. Progress and perspective in lowdimensional metal halide perovskites for optoelectronic applications. Sol RRL, 2018, 2: 1700186

2 Dou L, Wong AB, Yu Y, et al. Atomically thin two-dimensional organic-inorganic hybrid perovskites. Science, 2015, 349: 15181521

3 Hu J, Yan L, You W. Two-dimensional organic-inorganic hybrid perovskites: A new platform for optoelectronic applications. Adv Mater, 2018, 30: 1802041

4 Li L, Liu X, Li Y, et al. Two-dimensional hybrid perovskite-type ferroelectric for highly polarization-sensitive shortwave photodetection. J Am Chem Soc, 2019, 141: 2623-2629

5 Wang Q, Chen H, Liu G, et al. Control of organic-inorganic halide perovskites in solid-state solar cells: A perspective. Sci Bull, 2015, 60: $405-418$

6 Zhang HY, Song XJ, Chen XG, et al. Observation of vortex domains in a two-dimensional lead iodide perovskite ferroelectric. J Am Chem Soc, 2020, 142: 4925-4931

7 Huo C, Cai B, Yuan Z, et al. Two-dimensional metal halide perovskites: Theory, synthesis, and optoelectronics. Small Methods, 2017, 1: 1600018

8 Misra RK, Cohen BE, Iagher L, et al. Low-dimensional organicinorganic halide perovskite: Structure, properties, and applications. ChemSusChem, 2017, 10: 3712-3721

9 Smith IC, Hoke ET, Solis-Ibarra D, et al. A layered hybrid perovskite solar-cell absorber with enhanced moisture stability. Angew Chem Int Ed, 2014, 53: 11232-11235

10 Smith MD, Connor BA, Karunadasa HI. Tuning the luminescence of layered halide perovskites. Chem Rev, 2019, 119: 3104-3139

11 Wang $\mathrm{Z}$, Jingjing $\mathrm{Q}$, Wang $\mathrm{X}$, et al. Two-dimensional light-emitting materials: Preparation, properties and applications. Chem Soc Rev, 2018, 47: 6128-6174

12 Li W, Wang Z, Deschler F, et al. Chemically diverse and multifunctional hybrid organic-inorganic perovskites. Nat Rev Mater, 2017, 2: 16099

13 Mao L, Stoumpos CC, Kanatzidis MG. Two-dimensional hybrid halide perovskites: Principles and promises. J Am Chem Soc, 2019, 141: 1171-1190

14 Saparov B, Mitzi DB. Organic-inorganic perovskites: Structural versatility for functional materials design. Chem Rev, 2016, 116: 4558-4596

15 Ye HY, Liao WQ, Hu CL, et al. Bandgap engineering of lead-halide perovskite-type ferroelectrics. Adv Mater, 2016, 28: 2579-2586

16 Du ZY, Xu TT, Huang B, et al. Switchable guest molecular dynamics in a perovskite-like coordination polymer toward sensitive 
thermoresponsive dielectric materials. Angew Chem Int Ed, 2015, 54: 914-918

17 Fan FR, Wu H, Nabok D, et al. Electric-magneto-optical Kerr effect in a hybrid organic-inorganic perovskite. J Am Chem Soc, 2017, 139: $12883-12886$

18 Shang R, Wang ZM, Gao S. A 36-fold multiple unit cell and switchable anisotropic dielectric responses in an ammonium magnesium formate framework. Angew Chem Int Ed, 2015, 54: 2534-2537

19 Stroppa A, Barone P, Jain P, et al. Hybrid improper ferroelectricity in a multiferroic and magnetoelectric metal-organic framework. Adv Mater, 2013, 25: 2284-2290

20 Sun Z, Luo J, Chen T, et al. Distinct molecular motions in a switchable chromophore dielectric $4-N, N$-dimethylamino- $4^{\prime}-N^{\prime}$ methylstilbazolium trifluoromethanesulfonate. Adv Funct Mater, 2012, 22: 4855-4861

21 Zhang W, Cai Y, Xiong RG, et al. Exceptional dielectric phase transitions in a perovskite-type cage compound. Angew Chem Int Ed, 2010, 49: 6608-6610

22 Zhang Y, Ye HY, Cai HL, et al. Switchable dielectric, piezoelectric, and second-harmonic generation bistability in a new improper ferroelectric above room temperature. Adv Mater, 2014, 26: 45154520

23 Zhang $\mathrm{T}$, Chu L, Zhang Z, et al. Full-temperature covered switching material with triple optic-dielectric states in a lead-free hybrid perovskite. Sci China Mater, 2020, 63: 2281-2288

24 Xu WJ, He CT, Ji CM, et al. Molecular dynamics of flexible polar cations in a variable confined space: Toward exceptional two-step nonlinear optical switches. Adv Mater, 2016, 28: 5886-5890

25 Zhang W, Ye HY, Graf R, et al. Tunable and switchable dielectric constant in an amphidynamic crystal. J Am Chem Soc, 2013, 135: 5230-5233

26 Zhang WY, Ye Q, Fu DW, et al. Optoelectronic duple bistable switches: A bulk molecular single crystal and unidirectional ultraflexible thin film based on imidazolium fluorochromate. Adv Funct Mater, 2017, 27: 1603945

27 Zhang Y, Liao WQ, Fu DW, et al. The first organic-inorganic hybrid luminescent multiferroic: (Pyrrolidinium) $\mathrm{MnBr}_{3}$. Adv Mater, 2015, 27: 3942-3946

28 Ye HY, Zhou QH, Niu XH, et al. High-temperature ferroelectricity and photoluminescence in a hybrid organic-inorganic compound: (3-Pyrrolinium) $\mathrm{MnCl}_{3}$. J Am Chem Soc, 2015, 137: 13148-13154

29 Karmakar A, Dodd MS, Agnihotri S, et al. $\mathrm{Cu}(\mathrm{II})$-doped $\mathrm{Cs}_{2} \mathrm{SbAgCl}_{6}$ double perovskite: A lead-free, low-bandgap material. Chem Mater, 2018, 30: 8280-8290

30 Tan Z, Li J, Zhang C, et al. Highly efficient blue-emitting Bi-doped $\mathrm{Cs}_{2} \mathrm{SnCl}_{6}$ perovskite variant: Photoluminescence induced by impurity doping. Adv Funct Mater, 2018, 28: 1801131

31 van der Stam W, Geuchies JJ, Altantzis T, et al. Highly emissive divalent-ion-doped colloidal $\mathrm{CsPb}_{1-x} \mathrm{M}_{x} \mathrm{Br}_{3}$ perovskite nanocrystals through cation exchange. J Am Chem Soc, 2017, 139: 4087-4097

32 Zhang X, Li L, Sun Z, et al. Rational chemical doping of metal halide perovskites. Chem Soc Rev, 2019, 48: 517-539

33 Das Adhikari S, Dutta SK, Dutta A, et al. Chemically tailoring the dopant emission in manganese-doped $\mathrm{CsPbCl}_{3}$ perovskite nanocrystals. Angew Chem Int Ed, 2017, 56: 8746-8750

34 Liu W, Lin Q, Li $\mathrm{H}$, et al. $\mathrm{Mn}^{2+}$-doped lead halide perovskite nanocrystals with dual-color emission controlled by halide content. J Am Chem Soc, 2016, 138: 14954-14961

35 Peng Y, Li L, Ji C, et al. Tailored synthesis of an unprecedented Pb-
Mn heterometallic halide hybrid with enhanced emission. J Am Chem Soc, 2019, 141: 12197-12201

36 Mir WJ, Jagadeeswararao M, Das S, et al. Colloidal Mn-doped cesium lead halide perovskite nanoplatelets. ACS Energy Lett, 2017, 2: 537-543

37 Zhou G, Guo S, Zhao J, et al. Unraveling the mechanochemical synthesis and luminescence in Mn II-based two-dimensional hybrid perovskite $\left(\mathrm{C}_{4} \mathrm{H}_{9} \mathrm{NH}_{3}\right)_{2} \mathrm{PbCl}_{4}$. Sci China Mater, 2019, 62: 1013-1022

38 Zhou G, Jiang X, Molokeev M, et al. Optically modulated ultrabroad-band warm white emission in $\mathrm{Mn}^{2+}$-doped $\left(\mathrm{C}_{6} \mathrm{H}_{18} \mathrm{~N}_{2} \mathrm{O}_{2}\right)$ $\mathrm{PbBr}_{4}$ hybrid metal halide phosphor. Chem Mater, 2019, 31: 57885795

39 Harada J, Shimojo T, Oyamaguchi $\mathrm{H}$, et al. Directionally tunable and mechanically deformable ferroelectric crystals from rotating polar globular ionic molecules. Nat Chem, 2016, 8: 946-952

40 Shi C, Han XB, Zhang W. Structural phase transition-associated dielectric transition and ferroelectricity in coordination compounds. Coord Chem Rev, 2019, 378: 561-576

41 You YM, Liao WQ, Zhao D, et al. An organic-inorganic perovskite ferroelectric with large piezoelectric response. Science, 2017, 357: 306-309

42 Jing Z, Xiong Y, Yao J, et al. Recent progress in molecular ferroelectrics with perovskite structure. Chin Sci Bull, 2020, 65: 916-930

43 Gao JX, Zhang WY, Wu ZG, et al. Enantiomorphic perovskite ferroelectrics with circularly polarized luminescence. J Am Chem Soc, 2020, 142: 4756-4761

44 Huang RK, Xiao ZF, Liu DX, et al. Unprecedented water-controlled rotator-stator conversion of supramolecular rotors in crystals. Chem Commun, 2019, 55: 7159-7162

45 Parobek D, Roman BJ, Dong Y, et al. Exciton-to-dopant energy transfer in Mn-doped cesium lead halide perovskite nanocrystals. Nano Lett, 2016, 16: 7376-7380

46 Ye HY, Ge JZ, Tang YY, et al. Molecular ferroelectric with most equivalent polarization directions induced by the plastic phase transition. J Am Chem Soc, 2016, 138: 13175-13178

47 Zhang Y, Song XJ, Zhang ZX, et al. Piezoelectric energy harvesting based on multiaxial ferroelectrics by precise molecular design. Matter, 2020, 2: 697-710

48 Liao WQ, Zhang Y, Hu CL, et al. A lead-halide perovskite molecular ferroelectric semiconductor. Nat Commun, 2015, 6: 7338

49 Milman V, Winkler B, White JA, et al. Electronic structure, properties, and phase stability of inorganic crystals: A pseudopotential plane-wave study. Int J Quant Chem, 2000, 77: 895-910

50 Sun Z, Zeb A, Liu S, et al. Exploring a lead-free semiconducting hybrid ferroelectric with a zero-dimensional perovskite-like structure. Angew Chem Int Ed, 2016, 55: 11854-11858

Acknowledgements This work was supported by the National Natural Science Foundation of China (21991141), the Natural Science Foundation of Zhejiang Province (LZ20B010001) and Zhejiang Normal University.

Author contributions Zhang ZX conceived and conducted the experiments, analyzed the data and wrote the paper; Su CY and Zhang T carried out the dielectric characterizations; Gao JX assisted data analysis; $\mathrm{Su} \mathrm{CY}$ and Fu DW provided suggestions to the final version of the manuscript; Fu DW guided and supervised this work. All authors contributed to the manuscript. 
Conflict of interest The authors declare that they have no conflict of interest.

Supplementary information Experimental details and supporting data are available in the online version of the paper.

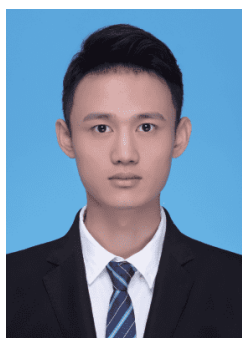

Zhi-Xu Zhang is a $\mathrm{PhD}$ candidate in the group of Jiangsu Key Laboratory for Science and Applications of Molecular Ferroelectrics, Southeast University. His current research mainly focuses on multifunctional perovskite materials with optical-electrical response.

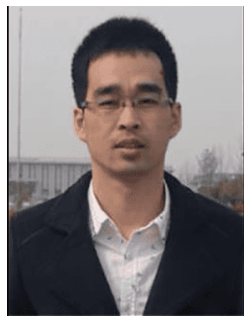

Da-Wei Fu is a professor of Jiangsu Key Laboratory for Science and Applications of Molecular Ferroelectrics in Southeast University, a recipient of the National Excellent Young Scientists Fund and a new century talent of the Ministry of Education. His current research interest focuses on high-performance molecular dielectric/ferroelectric materials.

\section{机械化学促成可调谐光-电多功能响应二维杂化} 钙钛矿材料

张志旭 ${ }^{1}$, 苏昌远 ${ }^{1}$, 高继兴 ${ }^{2}, 弓^{2}$ 铁 $^{1}$, 付大伟 ${ }^{1,2^{*}}$

摘要 二维有机-无机杂化钙钛矿因在光伏、光电子等领域的巨大 应用潜力而备受关注. 此外, 该类材料具有突出的结构可调性和材 料稳定性, 为功能性质的设计调控及器件应用提供了丰富的材料 设计平台. 然而, 将多种物理通道的性质整合实现材料的多功能性 仍具有挑战性, 而对其进行快速有效的调节更是难上加难. 迄今为 止, 尚未成功实现可调谐的光电多通道响应材料. 本文成功开发了 一种简便有效的机械力化学合成方法, 可实现二维杂化钙钛矿中 的多功能光电集成和调控. 温和的外部机械刺激可快速形成锰掺 杂的二维杂化钲钛矿 (Cyclopropylammonium) ${ }_{2} \mathrm{~Pb}_{1-x} \mathrm{Mn}_{x} \mathrm{Br}_{4}$, 并迅 速调节其光学性质并诱导高温介电开关，实现高效的蓝色、白 色、粉红色和橙色苂光特性. 这项工作将为多功能光电响应材料 的快速有效设计提供新的视角, 也将为低成本、高效率智能设备 的进一步开发和应用提供新的机遇. 